\title{
Health-care activities protect and restore health and save lives. But what about the waste and by-products they generate? \\ Khan $\mathbf{M K}^{1}$
}

Hospital waste management needs more attention in our country as until now it is not up to the mark. Improper handling of medical wastes, which is common in Bangladesh, could adversely affect the hospital environment and community at large, and poses a serious threat to public health. ${ }^{1}$

Of the total amount of waste generated by healthcare activities, about $85 \%$ is general, non-hazardous waste comparable to domestic waste. The remaining $15 \%$ is considered hazardous material that may be infectious, chemical or radioactive.

Hospital waste produced in our country per bed per day is approximately $1 \mathrm{~kg}$, according to a survey conducted by WHO in 2001. In North America quantity is around 7-10 kg \& in Eastern Asia it is 1.8$4 \mathrm{~kg}^{2}$

The proportion of this waste that would be classified as hazardous waste by World Health Organization (WHO) guidelines was found to be approximately $21 \%$. The amount of waste, and the proportion of hazardous waste, was found to vary significantly with the size and type of Health care establishment. ${ }^{3}$

The major sources of health-care waste are: Hospitals and other health facilities, laboratories and research centers, mortuary and autopsy centers, animal research and testing laboratories, blood banks and collection services, nursing homes for the elderly

\section{Types of waste}

Waste and by-products cover a diverse range of materials, as the following list illustrates: Infectious waste: waste contaminated with blood and other bodily fluids (e.g. from discarded diagnostic samples), cultures and stocks of infectious agents from laboratory work (e.g. waste from autopsies and infected animals from laboratories), or waste from patients with infections (e.g. swabs, bandages and disposable medical devices).

Pathological waste: human tissues, organs or fluids, body parts and contaminated animal carcasses;
Sharps waste: syringes, needles, disposable scalpels and blades, etc.

Chemical waste: for example solvents and reagents used for laboratory preparations, disinfectants, sterilant and heavy metals contained in medical devices (e.g. mercury in broken thermometers) and batteries.

Pharmaceutical waste: expired, unused and contaminated drugs and vaccines; Cyctotoxic waste: waste containing substances with genotoxic properties (i.e. highly hazardous substances that are, mutagenic, teratogenic or carcinogenic), such as cytotoxic drugs used in cancer treatment and their metabolites.

Radioactive waste: such as products contaminated by radionuclides including radioactive diagnostic material or radiotherapeutic materials; and Nonhazardous or general waste: waste that does not pose any particular biological, chemical, radioactive or physical hazard.

Every year an estimated 16 billion injections are administered worldwide, but not all of the needles and syringes are properly disposed of afterwards.

Open burning and incineration of health care wastes can, under some circumstances, result in the emission of dioxins, furans, and particulate matter.

\section{1 * Prof. M. Karim Khan}

MBBS, MCPS, DCH, DTM \& H, MPH (Hospital Management)

Director Hospital

Community Based Medical College Hospital, Mymensingh. Bangladesh

\section{*Address of correspondence}

Phone: +88 01711350724

Email: mmukkhan@gmail.com 
Measures to ensure the safe and environmentally sound management of health care wastes can prevent adverse health and environmental impacts from such waste including the unintended release of chemical or biological hazards, including drugresistant microorganisms, into the environment thus protecting the health of patients, health workers, and the general public.

Health-care waste contains potentially harmful microorganisms that can infect hospital patients, health workers and the general public. Other potential hazards may include drug-resistant microorganisms which spread from health facilities into the environment.

Adverse health outcomes associated with health care waste and by-products also include: Sharpsinflicted injuries; Toxic exposure to pharmaceutical products, in particular, antibiotics and cytotoxic drugs released into the surrounding environment, and to substances such as mercury or dioxins, during the handling or incineration of health care wastes; chemical burns arising in the context of disinfection, sterilization or waste treatment activities; air pollution arising as a result of the release of particulate matter during medical waste incineration; thermal injuries occurring in conjunction with open burning and the operation of medical waste incinerators; and radiation burns.

Injections with contaminated needles and syringes in low- and middle-income countries have reduced substantially in recent years, partly due to efforts to reduce reuse of injection devices. Despite this progress, in 2010, unsafe injections were still responsible for as many as 33800 new HIV infections, 1.7 million hepatitis $B$ infections and 315 000 hepatitis $\mathrm{C}$ infections. ${ }^{4}$

A person who experiences one needle stick injury from a needle used on an infected source patient has risks of $30 \%, 1.8 \%$, and $0.3 \%$ respectively of becoming infected with HBV, HCV and HIV.

Additional hazards occur from scavenging at waste disposal sites and during the handling and manual sorting of hazardous waste from health-care facilities. These practices are common in many regions of the world, especially in low- and middleincome countries. The waste handlers are at immediate risk of needle-stick injuries and exposure to toxic or infectious materials.

In 2015, a joint WHO/UNICEF assessment found that just over half (58\%) of sampled facilities from 24 countries had adequate systems in place for the safe disposal of health care waste. ${ }^{5}$

\section{Environmental Impact}

Treatment and disposal of healthcare waste may pose health risks indirectly through the release of pathogens and toxic pollutants into the environment. The disposal of untreated health care wastes in landfills can lead to the contamination of drinking, surface, and ground waters if those landfills are not properly constructed.

The treatment of health care wastes with chemical disinfectants can result in the release of chemical substances into the environment if those substances are not handled, stored and disposed in an environmentally sound manner.

Incineration of waste has been widely practiced, but inadequate incineration or the incineration of unsuitable materials results in the release of pollutants into the air and in the generation of ash residue. Incinerated materials containing or treated with chlorine can generate dioxins and furans, which are human carcinogens and have been associated with a range of adverse health effects. Incineration of heavy metals or materials with high metal content (in particular lead, mercury and cadmium) can lead to the spread of toxic metals in the environment.

Only modern incinerators operating at $850-1100^{\circ} \mathrm{C}$ and fitted with special gas-cleaning equipment are able to comply with the international emission standards for dioxins and furans.

Alternatives to incineration such as autoclaving, microwaving, steam treatment integrated with internal mixing, which minimize the formation and release of chemicals or hazardous emissions should be given consideration in settings where there are sufficient resources to operate and maintain such systems and dispose of the treated waste. ${ }^{6}$

In addition, WHO and UNICEF together with partners in 2015 launched a global initiative to ensure that all health care facilities have adequate water, sanitation and hygiene services. This includes addressing health care waste. ${ }^{7}$ 
Unfortunately the management of hospital waste in our country still not very adequate $\&$ upto the mark, it demands more attention for better management.

\section{References}

1. Sarker MA1, Harun-Or-Rashid M2, Hirosawa T1, Abdul Hai MS3, Siddique MR4, Sakamoto J5, Hamajima N1, Evaluation of knowledge, practices, and possible barriers among healthcare providers regarding medical waste management in Dhaka, Bangladesh. Med SciMonit. $2014 \quad$ Dec 9;20:2590-7. doi:10.12659/MSM.890904.

2. Rahman AKM. Situation assessment \& analysis of hospital waste management pilot study. DGHS, Dhaka, Bangladesh

3. Quantitative assessment of medical waste generation in the capital city of Bangladesh; Quantitative assessment of medical waste generation in the capital city of Bangladesh;
Waste Manag. 2009 Aug;29(8):2392-7. doi:10.1016/j.wasman.2009.03.021. Epub 2009 Apr 16

4. US Environment protection agency, 40 CFR parts 22 \& 259, Standards for the tracking \& management of medical waste. Interim final rules \& requests for comments, Federal registrar, Vol. 54:56, March 24, 1989.

5. Pépin J, Abou Chakra CN, Pépin E, Nault V, Valiquette L. Evolution of the global burden of viral infections from unsafe medical injections, 2000-2010.PLoSOne. 2014 Jun 9;9(6):e99677.

6. Akter N1, Hussain Z, Trankler J, Parkpian P. Hospital waste management and it's probable health effect: a lesson learned from Bangladesh; Indian J Environ Health. 2002 Apr;44(2):124-37.

7. WHO/UNICEF,2015. Water, sanitation and hygiene in health care facilities: status in low-and middle-income countries. World Health Organization, Geneva. 